\title{
Intra-articular tranexamic acid as an adjunct to intravenous tranexamic acid for simultaneous bilateral total knee arthroplasty: a randomized double-blind, placebo-controlled trial
}

\author{
Sachiyuki Tsukada ${ }^{* *}$ D, Kenji Kurosaka ${ }^{1}$, Masahiro Nishino ${ }^{1}$, Tetsuyuki Maeda², Yoshiharu Yonekawa ${ }^{3}$ and
} Naoyuki Hirasawa ${ }^{1}$

\begin{abstract}
Background: Intra-articular tranexamic acid (TXA) as an adjunct to intravenous TXA was reported to decrease perioperative blood loss during unilateral total knee arthroplasty (TKA). However, there have been no randomized controlled trials comparing intravenous versus combined intravenous and intra-articular TXA administration in patients undergoing simultaneous bilateral TKA.

Methods: We randomly assigned 77 patients with 154 involved knees undergoing simultaneous bilateral TKA to the intravenous TXA group (intra-articular placebo for each knee) or combined TXA group (1000 mg of intraarticular TXA for each knee) with 1:1 treatment allocation. In both groups, $1000 \mathrm{mg}$ of TXA was given intravenously twice, just before surgery and $6 \mathrm{~h}$ after the initial administration. Other perioperative medications, surgical procedures, and blood management strategies were the same for all patients. The primary outcome was perioperative blood loss calculated from blood volume and change in hemoglobin from preoperative to postoperative day 3.

Results: Intention-to-treat analysis showed no statistically significant differences in perioperative blood loss until postoperative day $3(1067 \pm 403 \mathrm{~mL}$ in the intravenous TXA group vs. $997 \pm 345 \mathrm{~mL}$ in the combined TXA group [95\% Cl, -240 to $100 \mathrm{~mL}], P=0.42$ ). No patients required allogenic blood transfusion. The incidence of thrombotic events did not differ between groups (12\% in the intravenous TXA group vs. $9 \%$ in the combined TXA group; $P=0.73$.
\end{abstract}

Conclusions: The addition of intra-articular TXA did not reduce perioperative blood loss in patients undergoing simultaneous bilateral TKA compared with placebo.

Trial registration: University Hospital Medical Information Network UMIN000026137. Registered 14 February 2017.

Keywords: Knee, Primary arthroplasty, Blood loss, Transfusion, Complication

\footnotetext{
* Correspondence: s8058@nms.ac.jp

${ }^{1}$ Department of Orthopaedic Surgery, Hokusuikai Kinen Hospital, 3-2-1

Higashihara, Mito, Ibaraki 310-0035, Japan

Full list of author information is available at the end of the article
}

(c) The Author(s). 2019 Open Access This article is distributed under the terms of the Creative Commons Attribution 4.0 International License (http://creativecommons.org/licenses/by/4.0/), which permits unrestricted use, distribution, and reproduction in any medium, provided you give appropriate credit to the original author(s) and the source, provide a link to the Creative Commons license, and indicate if changes were made. The Creative Commons Public Domain Dedication waiver (http://creativecommons.org/publicdomain/zero/1.0/) applies to the data made available in this article, unless otherwise stated. 


\section{Introduction}

Although tranexamic acid (TXA) has become an essential component of modern blood preservation strategies for patients undergoing total knee arthroplasty (TKA), the most effective administration route remains arguable [1, 2]. The intravenous route has been the most common route for TXA administration [3]. Meanwhile, intra-articular TXA administration has been shown to have similar effectiveness to intravenous TXA administration regarding blood preservation after TKA $[1,4]$. Many recent randomized controlled trials (RCTs) concluded that intra-articular TXA as an adjunct to intravenous TXA could reduce blood loss after unilateral TKA without increasing thrombotic events compared with intravenous TXA administration alone $[5,6]$. However, several RCTs reported that perioperative blood loss did not differ between combined intravenous and intraarticular TXA and intravenous TXA alone [7, 8].

The management of perioperative blood loss of simultaneous bilateral TKA is more challenging than unilateral or staged bilateral TKA [9]. Only one retrospective study compared the effectiveness of intravenous TXA and combined intravenous and intra-articular TXA in simultaneous bilateral TKA [10]. Stricter evidence is required to determine the effective administration route of TXA for simultaneous bilateral TKA.

We conducted a double-blind, placebo-controlled RCT to compare the clinical effectiveness of combined intravenous and intra-articular TXA with intravenous TXA alone in patients undergoing simultaneous bilateral TKA. The hypothesis for this RCT was that perioperative blood loss would be lower in patients receiving combined intravenous and intra-articular TXA than in those receiving intravenous TXA alone without increasing thrombotic events.

\section{Materials and methods Trial design}

We conducted a single-center, double-blind, clinical superiority RCT in which patients who underwent simultaneous bilateral TKA were randomly assigned in a 1:1 ratio to receive either a combination of $1000 \mathrm{mg}$ of TXA intravenously and $1000 \mathrm{mg}$ of intra-articular TXA in each knee (combined TXA group) or $1000 \mathrm{mg}$ of TXA intravenously and intra-articular normal saline in each knee (intravenous TXA group). The institutional review board provided ethical oversight and study approval. All patients provided written informed consent before inclusion. The study was registered with the University Hospital Medical Information Network, number UMIN000026137.

\section{Study participants}

We recruited participants via one treating clinician (ST) between February 2017 and January 2019. Patients were considered for inclusion if they were 20 years of age or older and medically fit for simultaneous bilateral TKA. The protocol-specified exclusion criteria were patients with known allergic reaction to TXA, patients with preoperative hemoglobin level under $11.0 \mathrm{~g} / \mathrm{dL}$, patients who refused blood products, and patients who were enrolled in another interventional clinical trial within 6 months prior to surgery.

To maintain generalizability, we included patients receiving chronic antithrombotic therapy. In such patients, we applied a continued strategy of chronic antithrombotic therapy; chronic antithrombotic therapy with antithrombotic agents, including antiplatelet agents, vitamin $\mathrm{K}$ antagonists, and direct oral anticoagulants were continued during the perioperative period, including the day of surgery [11]. Our protocol-specified criteria did not exclude patients with a history of prior thromboembolic events.

\section{Randomization and blinding}

The individual patients were randomly allocated to treatment on a 1:1 basis. We generated a sequence of random numbers from 0 to 99 using computer software ( $R$; The R Foundation for Statistical Computing, Vienna, Austria). We prepared sufficient number of opaque envelopes into which these randomized numbers were placed. A sealed envelope was selected just after starting TKA of the first knee by the allocating staff who were not otherwise involved in the trial. Patients with even numbers were allocated to the intravenous TXA group and those with odd numbers were allocated to the combined TXA group.

\section{Interventions}

The study intervention was intra-articular TXA or placebo as an adjunct to intravenous TXA. Thus, the study treatments were combined intravenous and intra-articular TXA or intravenous TXA and intra-articular normal saline. The study drugs were identical in appearance because the TXA solution was transparent. All other elements of perioperative interventions remained the same for all both groups.

In the combined TXA group, patients received 1000 mg of TXA intravenously (Transamin; Daiichi-Sankyo, Tokyo, Japan) just before the skin incision in the first knee. After implantation of the prosthesis, we closed the capsule and retinaculum. Then, we injected $1000 \mathrm{mg}$ of TXA (10 mL of $100 \mathrm{mg} / \mathrm{mL}$ TXA) intra-articularly into each knee through the medial patellar retinaculum using a 23-gauge needle [10]. Thus, a total of $3000 \mathrm{mg}$ of TXA was administered in the operating theater for patients allocated to the combined TXA group. In the ward, another $1000 \mathrm{mg}$ of TXA was given intravenously $6 \mathrm{~h}$ after the initial intravenous administration. 
In the intravenous TXA group, $1000 \mathrm{mg}$ of TXA was similarly administered intravenously just before the skin incision in the first knee. After closing the capsule and retinaculum, $10 \mathrm{~mL}$ of normal saline was administered intra-articularly into each knee. For the patients allocated to the intravenous TXA group, $1000 \mathrm{mg}$ of TXA was administered in the operating theater. Six hours later, we administered another $1000 \mathrm{mg}$ of TXA intravenously.

\section{Pre- and postoperative medication}

No thromboprophylaxis was prescribed to prevent venous thromboembolism during the study period. For patients who had chronic antithrombotic therapy with antithrombotic agents, all antithrombotic agents were continued during the perioperative period [11].

Antibiotic prophylaxis with $1000 \mathrm{mg}$ of cefazolin (Cefamezin; Astellas, Tokyo, Japan) was intravenously administered perioperatively.

All patients received an intraoperative periarticular injection of an analgesic solution containing $40 \mathrm{~mL}$ of ropivacaine (Anapeine, $7.5 \mathrm{mg} / \mathrm{mL}$; AstraZeneca, Osaka, Japan), $1.0 \mathrm{~mL}$ of morphine hydrochloride hydrate (10 $\mathrm{mg} / \mathrm{mL}$; Takeda), $0.6 \mathrm{~mL}$ of epinephrine (Bosmin, 1.0 $\mathrm{mg} / \mathrm{mL}$; Daiichi-Sankyo), $80 \mathrm{mg}$ of methylprednisolone (Sol Mercort; Fuji, Toyama, Japan), and $50 \mathrm{mg}$ of ketoprofen (Capisten; Kissei, Nagano, Japan) [12]. These agents were mixed with normal saline solution to achieve a combined volume of $120 \mathrm{~mL}$, and $60 \mathrm{~mL}$ of the mixture was injected into each knee [12]. For each knee, $40 \mathrm{~mL}$ of solution was injected into the extensor mechanism, pes anserinus, and anteromedial capsule just prior to arthrotomy, and the remaining $20 \mathrm{~mL}$ of solution was injected into the posterior capsule, posteromedial structures, and periarticular synovium just before implantation [13].

All patients received $4 \mathrm{mg}$ of oral non-steroidal antiinflammatory drug (lornoxicam, Lorcam; Taisho-Toyama, Tokyo, Japan) three times a day for postoperative pain relief.

\section{Anesthesia, surgery, and rehabilitation}

All simultaneous bilateral TKAs were performed sequentially with one surgical team under the same session of anesthesia; the operation on the second knee started after completion of wound closure on the first side.

All patients were managed with general anesthesia induced using short-acting volatile anesthetic (sevoflurane; Sevofrane, Maruishi, Tokyo, Japan) and intravenous anesthetic (propofol, Diprivan; AstraZeneca, Osaka, Japan). Anesthesia was maintained with sevoflurane and continuous infusion of short-acting opioid (remifentanil, Ultiva; Janssen, Tokyo, Japan). The details of intraoperative blood pressure management were left to the discretion of the anesthesiologists. The study protocol prohibited regional anesthesia.

All surgical procedures were performed by one of two orthopedic surgeons (ST and KK). No pneumatic tourniquet was used during the study period. An anterolateral incision was used in all surgeries [14]. A subvastus approach without patellar eversion was used except in patients with valgus knee alignment, for whom a lateral approach was used. All patients received a cemented, posterior-stabilized prosthesis. Intraoperative bone cutting and soft tissue balancing were performed using standardized techniques as reported previously [15]. We used intramedullary guides for femoral preparations and plugged the femoral canal with autologous bone. No drain was placed for any of the patients. An intermittent foot-pump system was routinely used to prevent deep vein thrombosis (DVT) before the patient began walking exercise. All patients underwent the same standardized postoperative rehabilitation regimen from the day after TKA.

\section{Blood management strategies}

The blood management strategies were performed in accordance with standardized methods as reported previously [10]. The study protocol included predonation of $800 \mathrm{~mL}$ or $400 \mathrm{~mL}$ of autologous blood for patients scheduled for simultaneous bilateral TKA. In patients who predonated $800 \mathrm{~mL}$ of blood, we collected $400 \mathrm{~mL}$ at 4 weeks before the TKA and another $400 \mathrm{~mL}$ at 2 weeks before the TKA. In patients who predonated 400 $\mathrm{mL}$ of blood, we collected $400 \mathrm{~mL}$ at 2 to 3 weeks before the TKA.

No predonated autologous blood was discarded during the study period. For patients who predonated $800 \mathrm{~mL}$ of blood, we routinely returned half $(400 \mathrm{~mL})$ of the $800-\mathrm{mL}$ predonation of autologous blood to the patient on the day of the simultaneous bilateral TKA and returned the remaining $400 \mathrm{~mL}$ on the day after TKA. For patients who predonated $400 \mathrm{~mL}$ of blood, we returned all $400 \mathrm{~mL}$ on the day of the TKA.

We did not employ any intraoperative blood salvage technique.

We planned additional allogenic blood transfusion for patients with a hemoglobin level of $<7.0 \mathrm{~g} / \mathrm{dL}$ who were asymptomatic and those with a hemoglobin level of < $10.0 \mathrm{~g} / \mathrm{dL}$ who had symptoms related to anemia.

\section{Pre- and postoperative screening for venous thromboembolism}

Plasma D-dimer level was measured as routine preoperative laboratory testing. Patients with plasma Ddimer level $>0.5 \mu \mathrm{g} / \mathrm{mL}$ were routinely tested for DVT by skilled clinical laboratory technicians using ultrasonography. 
At 1 day after TKA, all patients were screened for the presence of DVT by ultrasonography. At 7 days after TKA, patients were screened using the clinical model of Wells et al. [16], and those with a score of 3 or higher were again tested by ultrasonography. Pulmonary embolism was diagnosed based on clinical symptoms and enhanced chest computed tomography.

\section{Outcome measures}

\section{Primary outcome}

The prespecified primary outcome was the volume of perioperative blood loss, which was measured using the calculated blood volume and change in hemoglobin from preoperative to postoperative day 3 [10]. The blood volume of each patient was calculated using the formula reported by Nadler et al. [17]. For patients who received predonated autologous blood, we used the hemoglobin level prior to donation for this calculation. For patients who received allogenic blood, we planned to use a hemoglobin level of $19 \mathrm{~g} / \mathrm{dL}$ and $140 \mathrm{~mL}$ for 1 unit according to the data of the Japanese Red Cross Society.

The routine length of hospital stay in our institute was more than 7 days for all patient undergoing simultaneous bilateral TKA. No patients were unnecessarily hospitalized with the aim of measurements.

\section{Secondary outcomes}

The calculated blood loss at 7 days after TKA and the number of patients requiring allogeneic blood transfusion were compared between the two groups. Major bleeding and thrombotic events up to 3 months after TKA were investigated with special reference to DVT. Major bleeding and thrombotic events were defined according the criteria of Mantz et al. [18].

\section{Sample size calculation}

We hypothesized that the combined TXA group showed superior effectiveness to the intravenous TXA group in terms of perioperative blood loss. A previous RCT reported that the postoperative blood loss was lower, with mean value of $410 \mathrm{~mL}$ ( $95 \%$ confidence interval, 300 to $525 \mathrm{~mL}$ ) in the patients receiving combined intravenous and intra-articular TXA than patients receiving no TXA in simultaneous bilateral TKA [19]. The panel reached a consensus that the minimum value of $95 \%$ confidence interval of that study $(300 \mathrm{~mL})$ was employed for the sample size calculation of our study since there was no prior study clearly identifying what a minimally clinically important difference would be for the reduction of perioperative blood loss after simultaneous bilateral TKA. Thus, we powered this superiority trial to detect a 300$\mathrm{mL}$ difference in perioperative blood loss between the combined TXA group and intravenous TXA group. Based on a type I error rate of $5 \%$ and a power of $80 \%$, we calculated that a minimum of 32 patients would be required in each group. For power analysis, we used a standard deviation of $425 \mathrm{~mL}$ in perioperative blood loss noted in observational pilot data.

\section{Missing data and statistical analysis}

Prior to starting this RCT, we determined to use a complete case analysis for missing data of primary outcome as the number of missing values was predicted to be small for primary outcome [20].

Differences between treatment groups were assessed on an intention-to-treat basis. Differences in primary outcome between the two treatment groups were analyzed by Student's t-test. In addition, we calculated 95\% confidence intervals by comparing outcomes in the combined TXA group with intravenous TXA group. To evaluate the impact of the continuing chronic antithrombotic therapy, the volume of the perioperative blood loss until postoperative day 3 was also compared between four groups using analysis of variance: the combined TXA group with and without chronic antithrombotic therapy and the intravenous TXA group with and without chronic antithrombotic therapy.

For secondary outcomes and baseline characteristics, data were compared between the groups with Student's t-test for continuous variables, which are presented as means and standard deviations, and Fisher's exact test for categorical variables, which are presented as numbers and percentages.

A 2-sided $P$ value of 0.05 was considered to indicate statistical significance. All analyses were conducted using R software.

\section{Results}

Figure 1 shows the flow of these patients through the trial. A total of 77 patients consented to take part in the trial and underwent randomization: 43 to the combined TXA group and 34 to the intravenous TXA group. All analyses were conducted before the randomization code was broken. We obtained all data for the primary outcome of this study without missing data.

Table 1 summarizes the demographic characteristics of patients at baseline. Although we did not set the exclusion criteria for preoperative diagnosis, preoperative diagnoses were osteoarthritis of the knee for all patients included in this study. Mean volume of intraoperative blood loss was $117 \pm 68 \mathrm{~mL}$ for one knee $(n=154)$. There was no difference between two surgeons in terms of intraoperative blood loss $(121 \pm 73 \mathrm{~mL}$ vs. $101 \pm 40$ $\mathrm{mL}$ [95\% confidence interval of the difference, -58 to $18 \mathrm{~mL}], P=0.30$ ). 


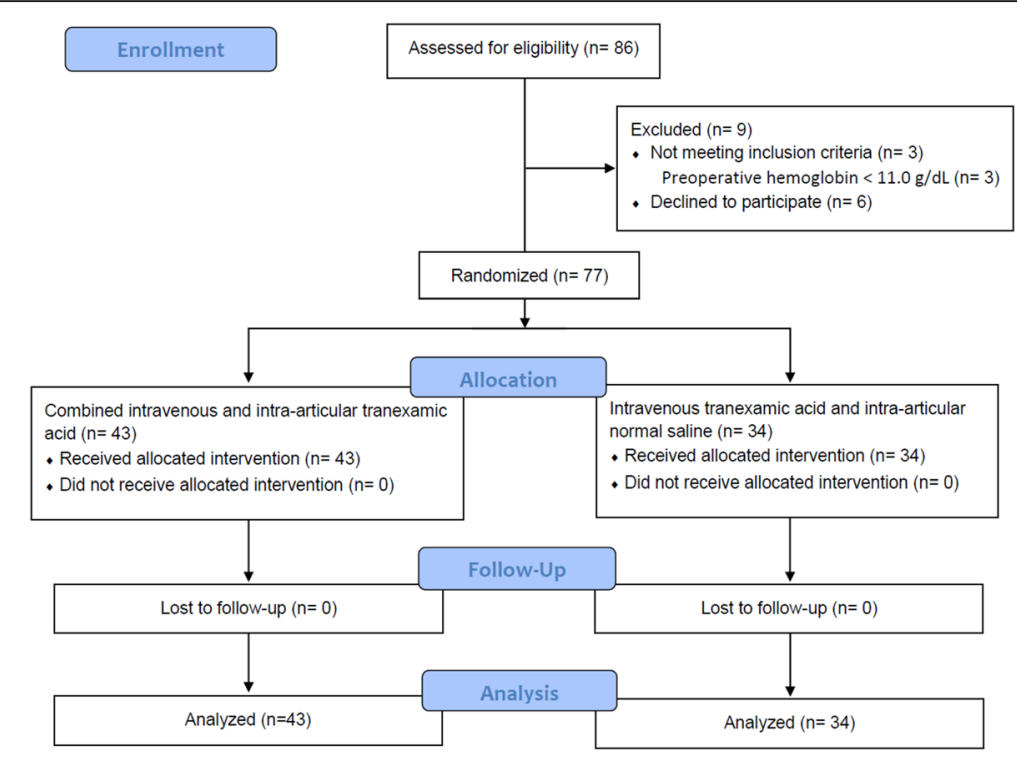

Fig. 1 Consent, randomization, and follow-up of participants in the randomized controlled trial comparing intravenous versus combined intravenous and intra-articular tranexamic acid for simultaneous bilateral total knee arthroplasty

\section{Primary outcome}

Intention-to-treat analysis showed that the volume of perioperative blood loss did not differ between treatment groups at 3 days after TKA $(997 \pm 345 \mathrm{~mL}$ in the combined TXA group vs. $1067 \pm 403 \mathrm{~mL}$ in the intravenous TXA group [95\% confidence interval of the

Table 1 Patient demographic and baseline clinical characteristics

\begin{tabular}{|c|c|c|c|}
\hline & $\begin{array}{l}\text { Combined } \\
\text { intravenous } \\
\text { and intra-articular } \\
\text { tranexamic } \\
\text { acid }(n=43)\end{array}$ & $\begin{array}{l}\text { Intravenous } \\
\text { tranexamic } \\
\text { acid and } \\
\text { intra-articular } \\
\text { normal saline } \\
(n=34)\end{array}$ & $P$-value \\
\hline Age, years & $75 \pm 6$ & $77 \pm 6$ & $0.22^{*}$ \\
\hline Sex (female/male) & $33 / 10$ & $28 / 6$ & $0.57+$ \\
\hline $\begin{array}{l}\text { Body mass index, } \\
\mathrm{kg} / \mathrm{m}^{2}\end{array}$ & $27.7 \pm 3.8$ & $28.1 \pm 4.2$ & $0.66^{*}$ \\
\hline $\begin{array}{l}\text { Receiving chronic } \\
\text { antithrombotic } \\
\text { therapy (yes/no) }\end{array}$ & $8 / 35$ & $5 / 29$ & $0.76+$ \\
\hline $\begin{array}{l}\text { History of Diabetes } \\
\text { Mellitus (yes/no) }\end{array}$ & $9 / 34$ & $6 / 28$ & $0.78+$ \\
\hline $\begin{array}{l}\text { Preoperative } \\
\text { hemoglobin, } \\
\mathrm{g} / \mathrm{dL}\end{array}$ & $13.2 \pm 1.3$ & $12.9 \pm 1.1$ & $0.34^{*}$ \\
\hline $\begin{array}{l}\text { Deep venous } \\
\text { thrombosis } \\
\text { detected with } \\
\text { preoperative } \\
\text { screening (yes/no) }\end{array}$ & $1 / 42$ & $0 / 34$ & $>0.99^{*}$ \\
\hline
\end{tabular}

Results are expressed as means \pm standard deviation, unless otherwise stated ${ }^{*} P$-values were determined with Student's $t$ test

$+P$-values were determined with the Fisher's exact test difference, -240 to $100 \mathrm{~mL}$ ], $P=0.42$ ). We found no statistically significant differences between patients with and without chronic antithrombotic therapy $(996 \pm 360 \mathrm{~mL}$ in the combined TXA group without chronic antithrombotic therapy vs. $1005 \pm 292 \mathrm{~mL}$ in the combined TXA group with chronic antithrombotic therapy vs. $1006 \pm 406 \mathrm{~mL}$ in the intravenous TXA group without chronic antithrombotic therapy vs. $1419 \pm 91 \mathrm{~mL}$ in the intravenous TXA group with chronic antithrombotic therapy, $P=0.11$ ).

\section{Secondary outcomes}

We saw no evidence of treatment group effects for any secondary outcome measures. The volume of perioperative blood loss until postoperative day 7 was not different between the two groups $(1147 \pm 446 \mathrm{~mL}$ in the combined TXA group vs. $1144 \pm 346 \mathrm{~mL}$ in the intravenous TXA group [95\% confidence interval of the difference, -182 to $189 \mathrm{~mL}], P=0.97)$. No patients required allogenic blood transfusion. There were no major bleeding events in study patients. Distal DVT was detected in four of 43 patients (9\%) in the combined TXA group and four of 34 patients $(12 \%)$ in the intravenous TXA group $(P=0.73)$. None of the study patients experienced major thrombotic events other than distal DVT.

\section{Discussion}

This double-blind, placebo-controlled RCT showed that additional intra-articular TXA to intravenous TXA was no more effective than placebo in reducing perioperative 
blood loss in patients undergoing simultaneous bilateral TKA.

This is the first RCT to compare the effectiveness of combined intravenous and intra-articular TXA and that of intravenous TXA alone for patients undergoing simultaneous bilateral TKA. Although TXA has been widely used in TKA to reduce perioperative blood loss [1, 21], the most effective route of administration for TXA remains moot [2]. In unilateral TKA, there has been conflicting evidence regarding the benefit of adding intraarticular TXA to intravenous TXA for perioperative blood preservation [5-8]. The results of our study did not support the use of intra-articular TXA as an adjunct to intravenous TXA.

The key limitation of this study was that this was a single-center study. There were specific features of our clinical practice, such as surgery without use of tourniquet and inpatient procedure. However, several investigators underscored that the effectiveness of TXA should be studied in the setting of TKA without use of a tourniquet as the modern fast-track setup must include both no use of tourniquet and effective administration of TXA [5, 10]. Moreover, the longer length of hospital stays compared with North America and Europe empowered us to perform routine blood tests at 3 days after TKA and DVT screening at 1 and 7 days after TKA for all study patients. It should be noted that this study excluded patients in whom the preoperative hemoglobin level was under $11.0 \mathrm{~g} / \mathrm{dL}$ as study protocol included the predonation of the autologous blood. Our findings, especially in terms of the incidence of patients requiring allogenic transfusion, would not be applicable to these patients. The sample size of this RCT allowed the assessment of total blood loss between groups. However, this RCT had limited power for the incidence of thrombotic events because the incidence was low.

The main strength of this study was the use of a randomized placebo-controlled design. One before-andafter study reported that combined intra-articular and intravenous TXA significantly reduced the perioperative blood loss compared to patients treated only with intravenous TXA in simultaneous bilateral TKA [10]. We believe that the randomized placebo-controlled design may bring different results from the before-andafter study as other previous RCTs revealed unexpected results [22-24]. We maintained high adherence to the study protocol and successful blinding of the patients, surgical teams, and outcome assessors and successful randomization and patient allocation concealment. We did not exclude patients with a history of prior thromboembolic events in this RCT. Recently published joint guidelines by five medical associations raised problems about the lack of high-level evidence to support the use of TXA in patients with a history of thromboembolic events [21].

\section{Conclusion}

This RCT showed that intra-articular TXA as an adjunct to intravenous TXA for simultaneous bilateral TKA did not result in decreased postoperative blood loss compared with placebo contrary to the study hypothesis.

\section{Abbreviations}

DVT: Deep vein thrombosis; RCT: Randomized controlled trial; TKA: Total knee arthroplasty; TXA: Tranexamic acid

\section{Acknowledgements}

The authors are grateful to Yoshie Kurosawa, Miyu Kaneda, and Miho Suzuki for their contributions as members of the data and safety monitoring committee.

\section{Authors' contributions}

ST developed the study design, recruited the participants, performed formal analyses and drafted and revised manuscript. ST and KK perforemed surgeries. TM contributed to standardizing anesthesia protocol. YY coordinated randomizing and blinding. MN and $\mathrm{NH}$ surpervised the study. All authors have read and approved the final manuscript.

\section{Funding}

There was no external source of funding for this study.

\section{Availability of data and materials}

The datasets used and/or analysed during the current study are not publicly available. Data are however available from the corresponding author on reasonable request.

\section{Ethics approval and consent to participate}

The study protocol was approved by the institutional review board of Hokusuikai Kinen Hospital. All patients provided written informed consent to participate.

\section{Consent for publication}

The publication of this study was approved by the institutional review board of Hokusuikai Kinen Hospital. All patients provided written informed consent to publish.

\section{Competing interests}

The authors declare that they have no competing interests.

\section{Author details}

${ }^{1}$ Department of Orthopaedic Surgery, Hokusuikai Kinen Hospital, 3-2-1 Higashihara, Mito, Ibaraki 310-0035, Japan. ²Department of Anesthesiology, Hokusuikai Kinen Hospital, Mito, Japan. ${ }^{3}$ Department of Nursing, Hokusuikai Kinen Hospital, Mito, Japan.

Received: 29 July 2019 Accepted: 10 October 2019

Published online: 22 October 2019

\section{References}

1. Poeran J, Rasul R, Suzuki S, Danninger T, Mazumdar M, Opperer M, Boettner F, Memtsoudis SG. Tranexamic acid use and postoperative outcomes in patients undergoing total hip or knee arthroplasty in the United States: retrospective analysis of effectiveness and safety. BMJ. 2014;349:94829.

2. Fillingham YA, Ramkumar DB, Jevsevar DS, Yates AJ, Shores P, Mullen K, Bini SA, Clarke HD, Schemitsch E, Johnson RL, Memtsoudis SG, Sayeed SA, Sah AP, Della Valle CJ. The efficacy of tranexamic acid in total knee arthroplasty: a network meta-analysis. J Arthroplasty. 2018;33:3090-3098.e1.

3. Lin ZX, Woolf SK. Safety, efficacy, and cost-effectiveness of tranexamic acid in orthopedic surgery. Orthopedics. 2016;39:119-30.

4. Gomez-Barrena E, Ortega-Andreu M, Padilla-Eguiluz NG, Pérez-Chrzanowska $H$, Figueredo-Zalve R. Topical intra-articular compared with intravenous tranexamic acid to reduce blood loss in primary total knee replacement: a 
double-blind, randomized, controlled, noninferiority clinical trial. J Bone Joint Surg Am. 2014:96:1937-44.

5. Nielsen CS, Jans $\varnothing$, Ørsnes T, Foss NB, Troelsen A, Husted H. Combined intra-articular and intravenous tranexamic acid reduces blood loss in total knee arthroplasty: a randomized, double-blind, placebo-controlled trial. J Bone Joint Surg Am. 2016:98:835-41.

6. Jain NP, Nisthane PP, Shah NA. Combined administration of systemic and topical tranexamic acid for total knee arthroplasty: can it be a better regimen and yet safe? A randomized controlled trial. J Arthroplast. 2016:31:542-7.

7. Song EK, Seon JK, Prakash J, Seol YJ, Park YJ, Jin C. Combined administration of IV and topical tranexamic acid is not superior to either individually in primary navigated TKA. J Arthroplast. 2017;32:37-42.

8. Huang Z, Ma J, Shen B, Pei F. Combination of intravenous and topical application of tranexamic acid in primary total knee arthroplasty: a prospective randomized controlled trial. J Arthroplast. 2014;29:2342-6.

9. Jankiewicz JJ, Sculco TP, Ranawat CS, Behr C, Tarrentino S. One-stage versus 2-stage bilateral total knee arthroplasty. Clin Orthop Relat Res. 1994;309:94-101.

10. Tsukada S, Wakui M. Combined intravenous and intra-articular tranexamic acid in simultaneous bilateral total knee arthroplasty without tourniquet use. JBJS Open Access. 2017;2:e0002.

11. Tsukada S, Kurosaka K, Nishino M, Maeda T, Hirasawa N. A strategy of continued antiplatelet agents, vitamin $\mathrm{K}$ antagonists, and direct oral anticoagulants throughout the perioperative period of total knee arthroplasty in patients receiving chronic antithrombotic therapy. JBJS Open Access. 2019:4:e0057.

12. Tsukada S, Wakui M, Hoshino A. Pain control after simultaneous bilateral total knee arthroplasty: a randomized controlled trial comparing periarticular injection and epidural analgesia. J Bone Joint Surg Am. 2015;97:367-73.

13. Tsukada S, Kurosaka K, Maeda T, lida A, Nishino M, Hirasawa N. Early stage periarticular injection during total knee arthroplasty may provide a better postoperative pain relief than late-stage periarticular injection: a randomized-controlled trial. Knee Surg Sports Traumatol Arthrosc. 2019;27:1124-31.

14. Tsukada S, Kurosaka K, Nishino M, Hirasawa N. Cutaneous Hypesthesia and kneeling ability after total knee arthroplasty: a randomized controlled trial comparing anterolateral and anteromedial skin incision. J Arthroplast. 2018; 33:3174-80

15. Tsukada S, Fujii T, Wakui M. Impact of soft tissue imbalance on knee flexion angle after posterior stabilized total knee arthroplasty. J Arthroplast. 2017;32: 2399-403.

16. Wells PS, Anderson DR, Rodger M, Forgie M, Kearon C, Dreyer J, Kovacs G, Mitchell M, Lewandowski B, Kovacs MJ. Evaluation of D-dimer in the diagnosis of suspected deep-vein thrombosis. N Engl J Med. 2003;349: 1227-35.

17. Nadler SB, Hidalgo JH, Bloch T. Prediction of blood volume in normal human adults. Surgery. 1962;51:224-32.

18. Mantz J, Samama CM, Tubach F, Devereaux PJ, Collet JP, Albaladejo P, Cholley B, Nizard R, Barré J, Piriou V, Poirier N, Mignon A, Schlumberger S, Longrois D, Aubrun F, Farèse ME, Ravaud P, Steg PG, Stratagem Study Group. Impact of preoperative maintenance or interruption of aspirin on thrombotic and bleeding events after elective non-cardiac surgery: the multicentre, randomized, blinded, placebo-controlled, STRATAGEM trial. Br J Anaesth. 2011;107:899-910.

19. Karaaslan F, Karaoğlu S, Mermerkaya MU, Baktir A. Reducing blood loss in simultaneous bilateral total knee arthroplasty: combined intravenous-intraarticular tranexamic acid administration: a prospective randomized controlled trial. Knee. 2015;22:131-5

20. Little RJ, D'Agostino R, Cohen ML, Dickersin K, Emerson SS, Farrar JT, Frangakis C, Hogan JW, Molenberghs G, Murphy SA, Neaton JD, Rotnitzky A, Scharfstein D, Shih WJ, Siegel JP, Stern H. The prevention and treatment of missing data in clinical trials. N Engl J Med. 2012;367:1355-60.

21. Fillingham YA, Ramkumar DB, Jevsevar DS, Yates AJ, Bini SA, Clarke HD, Schemitsch E, Johnson RL, Memtsoudis SG, Sayeed SA, Sah AP, Della Valle CJ. Tranexamic acid use in total joint arthroplasty: the clinical practice guidelines endorsed by the American Association of hip and Knee Surgeons, American Society of Regional Anesthesia and Pain Medicine, American Academy of Orthopaedic surgeons, hip society, and knee society. J Arthroplast. 2018;33:3065-9.
22. Echt DS, Liebson PR, Mitchell LB, Peters RW, Obias-Manno D, Barker AH, Arensberg D, Baker A, Friedman L, Greene HL, Huther ML, Richardson DW, The CAST Investigators. Mortality and morbidity in patients receiving encainide, flecainide, or placebo. The cardiac arrhythmia suppression trial. N Engl J Med. 1991;324:781-8.

23. Chlebowski RT, Hendrix SL, Langer RD, Stefanick ML, Gass M, Lane D, Rodabough RJ, Gilligan MA, Cyr MG, Thomson CA, Khandekar J, Petrovitch H, McTiernan A, WHI Investigators. Influence of estrogen plus progestin on breast cancer and mammography in healthy postmenopausal women: the Women's Health Initiative Randomized Trial. JAMA. 2003;289:3243-53.

24. Ismail-Beigi F, Craven T, Banerii MA, Basile J, Calles J, Cohen RM, Cuddihy R, Cushman WC, Genuth S, Grimm RH Jr, Hamilton BP, Hoogwerf B, Karl D, Katz L, Krikorian A, O'Connor P, Pop-Busui R, Schubart U, Simmons D, Taylor $H$, Thomas A, Weiss D, Hramiak I, ACCORD trial group. Effect of intensive treatment of hyperglycaemia on microvascular outcomes in type 2 diabetes: an analysis of the ACCORD randomised trial. Lancet. 2010;376:419-30.

\section{Publisher's Note}

Springer Nature remains neutral with regard to jurisdictional claims in published maps and institutional affiliations.
Ready to submit your research? Choose BMC and benefit from:

- fast, convenient online submission

- thorough peer review by experienced researchers in your field

- rapid publication on acceptance

- support for research data, including large and complex data types

- gold Open Access which fosters wider collaboration and increased citations

- maximum visibility for your research: over $100 \mathrm{M}$ website views per year

At BMC, research is always in progress.

Learn more biomedcentral.com/submissions 